
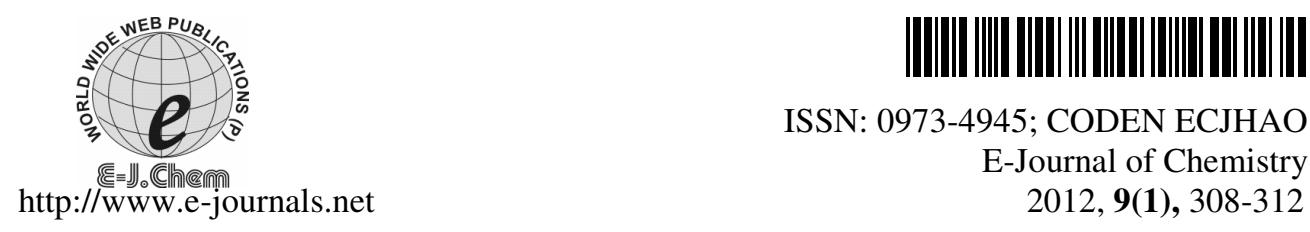

ISSN: 0973-4945; CODEN ECJHAO

E-Journal of Chemistry 2012, 9(1), 308-312

\title{
Gadolinium(III) Ion-Selective Electrode Based on 3-Methyl-1H-1,2,4-triazole-5-thiol
}

\author{
HASSAN ALI ZAMANI* and HOSSEIN BEHMADI \\ *Department of Applied Chemistry, Quchan branch, \\ Islamic Azad University, Quchan, Iran \\ Department of Chemistry, Mashhad branch, \\ Islamic Azad University, Mashhad, Iran \\ haszamani@yahoo.com
}

Received 16 May 2011; Accepted 15 July 2011

\begin{abstract}
The 3-methyl-1H-1,2,4-triazole-5-thiol (MTH) was used as a suitable ionophore for fabrication of a new gadolinium(III) ion selective potentiometric sensor. Nitrobenzene (NB) was used as plasticizing solvent mediator and sodium tetraphenyl borate (NaTPB) as an anion excluder. It displays a Nernstian response $(19.8 \pm 0.4 \mathrm{mV} /$ decade $)$ in the concentration range of $1.0 \times 10^{-7}$ to $1.0 \times 10^{-2} \mathrm{M}$ with the detection limit of $7.3 \times 10^{-8} \mathrm{M}$. The sensor has a very short response time $(<10 \mathrm{~s})$ and can be used the $\mathrm{pH}$ range of 2.9-8.4. The electrode was successfully applied as an indicator electrode for the gadolinium determination in titration with EDTA.
\end{abstract}

Keywords: PVC membrane, Sensor, Potentiometry, Ion selective electrode

\section{Introduction}

The quick determination of minute quantities of ionic species by simple methods is of special interest in analytical chemistry. During the last decade, there has been a renewed resurgence in developing potentiometric membrane electrodes as devices for rapid, accurate, low cost and nondestructive analysis of different samples with small volume samples. Ionselective sensors based on plasticized PVC membranes were successfully applied to the determination of many cations in various industrial, environmental and biochemical samples ${ }^{1-3}$.

Many techniques have been used for determination of Gd which most of them have been spectroscopic methods such as inductively coupled Plasma-mass spectrometry (ICP-MS), atomic emission spectroscopy, electron spin resonance, laser-based multi step resonance ionization, phosphorescence opto-sensing, high-resolution^I3-spectroscopy, timeresolved fluorimetry, spectrophotofluorimetric determination, quenching of gadolinium 
fluorescence and some nucleic methods. Recently, several greatly selective and sensitive PVC-membrane ion-selective electrodes for various metal ions have been reported ${ }^{4-21}$. This research focuses on the introduction of a highly Gd(IIII)-selective sensor based on 3-methyl1 $\mathrm{H}$-1,2,4-triazole-5-thiol (MTH) (Figure 1), as an ionophore for determination of Gd(III) ion concentration.

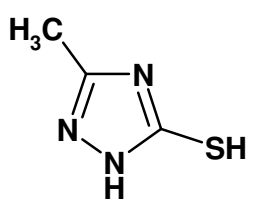

\section{Experimental}

Figure 1. Chemical structure of MTH

The ionophre MTH was synthesized as described elsewhere ${ }^{22}$. Nitrate and chloride salts of all cations and the reagent grades of dibutyl phthalate (DBP), nitrobenzene (NB) benzyl acetate (BA), acetophenone (AP), sodium tetraphenyl borate (NaTPB), tetrahydrofuran (THF) and high relative molecular weight PVC were all purchased from Merck Chemical Co. All reagents were used without any further modification. During the experiments, deionized distilled water was used.

\section{Electrode preparation and emf measurements}

Blending completely $30 \mathrm{mg}$ of powdered PVC, $66 \mathrm{mg}$ of NB and $2 \mathrm{mg}$ of NaTPB in $5 \mathrm{~mL}$ THF was the first step for the PVC membrane construction. The second step involved the addition of $2 \mathrm{mg} \mathrm{MTH}$. After well mixing the resulting mixture, it was transferred into a glass dish of $2 \mathrm{~cm}$ in diameter. A Pyrex tube $(5 \mathrm{~mm}$ i.d.) was dipped into the mixture for about $5 \mathrm{~s}$, so that a non-transparent membrane (about $0.3 \mathrm{~mm}$ in thickness) is formed. The tube was, then, removed from the mixture, kept at room temperature for about $12 \mathrm{~h}$ and filled with an internal filling solution $\left(1.0 \times 10^{-3} \mathrm{M} \mathrm{GdCl}_{3}\right)$. Finally, the electrode was conditioned by soaking in a $1.0 \times 10^{-3} \mathrm{M} \mathrm{GdCl}_{3}$ solution for $24 \mathrm{~h}^{23-33}$. As an internal reference electrode, a silver/silver chloride electrode was used.

All emf measurements were carried out with the following assembly: $\mathrm{Ag}-\mathrm{AgCll}$ $1.0 \times 10^{-3} \mathrm{~mol} \mathrm{~L}^{-1} \mathrm{GdCl}_{3}$ । PVC membrane: test solutionl $\mathrm{Hg}-\mathrm{Hg}_{2} \mathrm{Cl}_{2}, \mathrm{KCl}$ (satd). A Corning ion analyser $250 \mathrm{pH} / \mathrm{mV}$ meter was used for the potential measurements at $25.0{ }^{\circ} \mathrm{C}$. The activities were calculated according to the Debye-Huckel procedure.

\section{Results and Discussion}

In the preliminary experiment, MTH was used as a sensing material to prepare the PVC membrane ion-selective electrodes for a wide variety of cations, including alkali, alkaline earth, transition and heavy metal ions. Among different metal ions tested, $\mathrm{Gd}^{3+}$ ion seems to be suitably determined with the membrane sensor based on MTH. This observation is most probably due to the proper size of $\mathrm{Gd}^{3+}$ ion to the semi cavity of flexible MTH and the rapid exchange kinetics of the resulting MTH $-\mathrm{Gd}^{3+}$ complex.

In the next step, membrane ingredients effect (the nature and the amount of the ionophore, the nature and the amount of the used additive and the kind of plasticizer) were investigated on the potential response of the $\mathrm{Gd}^{3+}$ electrode ${ }^{34-39}$. The results are shown in Table 1. Among four plasticizers tested, NB offers the best sensitivity. This phenomenon can be due to the effect of plasticizer dielectric constant on the organic phase of the membrane. In accordance with Table 1 , using $2 \%$ of MTH in the membrane electrode 
displays Nernstian slope towards Gd(III) ion (membrane No. 3). However, the membrane sensor with the composition of 30\% PVC, 66\% NB, 2\% NaTPB and 2\% MTH displays a very nice Nernstian behavior.

Table 1. Optimization of the membrane ingredients

\begin{tabular}{|c|c|c|c|c|c|c|}
\hline \multirow{2}{*}{$\begin{array}{l}\text { Sensor } \\
\text { No. }\end{array}$} & \multicolumn{4}{|c|}{ Composition of the membrane, wt, $\%$} & \multirow{2}{*}{$\begin{array}{c}\text { Slope } \\
\left(\mathrm{mV} \mathrm{decade}^{-1}\right)\end{array}$} & \multirow{2}{*}{$\begin{array}{l}\text { Dynamic Linear } \\
\text { range }(\mathrm{M})\end{array}$} \\
\hline & PVC & Plasticizer & MTH & NaTPB & & \\
\hline 1 & 30 & $\mathrm{NB}, 68$ & 0 & 2 & $9.4 \pm 0.3$ & $1.0 \times 10^{-5}-1.0 \times 10^{-2}$ \\
\hline 2 & 30 & NB, 67 & 1 & 2 & $22.3 \pm 0.5$ & $1.0 \times 10^{-7}-1.0 \times 10^{-2}$ \\
\hline 3 & 30 & NB, 66 & 2 & 2 & $19.8 \pm 0.4$ & $1.0 \times 10^{-7}-1.0 \times 10^{-2}$ \\
\hline 4 & 30 & $\mathrm{NB}, 65$ & 3 & 2 & $19.4 \pm 0.3$ & $1.0 \times 10^{-5}-1.0 \times 10^{-2}$ \\
\hline 5 & 30 & NB, 68 & 2 & 0 & $14.9 \pm 0.7$ & $1.0 \times 10^{-7}-6.0 \times 10^{-2}$ \\
\hline 6 & 30 & $\mathrm{NB}, 67$ & 2 & 1 & $14.2 \pm 0.2$ & $1.0 \times 10^{-5}-1.0 \times 10^{-2}$ \\
\hline 7 & 30 & $\mathrm{NB}, 65$ & 2 & 3 & $16.6 \pm 0.3$ & $1.0 \times 10^{-7}-1.0 \times 10^{-2}$ \\
\hline 8 & 30 & $\mathrm{AP}, 66$ & 2 & 2 & $17.9 \pm 0.2$ & $1.0 \times 10^{-5}-1.0 \times 10^{-2}$ \\
\hline 8 & 30 & $\mathrm{BA}, 66$ & 2 & 2 & $16.8 \pm 0.5$ & $1.0 \times 10^{-6}-1.0 \times 10^{-2}$ \\
\hline 9 & 30 & $\mathrm{DBP}, 66$ & 2 & 2 & $17.3 \pm 0.4$ & $1.0 \times 10^{-5}-1.0 \times 10^{-2}$ \\
\hline
\end{tabular}

The potential response of the suggested MTH based sensor (composition no. 3) at varying gadolinium ion concentrations demonstrated a linear response to the gadolinium ion concentration in the range $1.0 \times 10^{-7}-1.0 \times 10^{-2} \mathrm{M}$ (Figure 2). The slope of the calibration graph was $19.8 \pm 0.4 \mathrm{mV}$ per decade. The detection limit was $7.3 \times 10^{-8} \mathrm{M}$.

The $\mathrm{pH}$ dependence of the membrane electrode was evaluated over a $\mathrm{pH}$ range of 2.0-11.0 at a $1.0 \times 10^{-3} \mathrm{M}$ of gadolinium ion concentration and the results are depicted in Figure 3. As can be seen, the potential remains fairly constant in the $\mathrm{pH}$ range of $2.9-8.4$ (the $\mathrm{pH}$ of the solutions was adjusted by either $\mathrm{HNO}_{3}$ or $\mathrm{NaOH}$ solutions). Beyond this range, a gradual change in the potential was detected. The observed potential drift at the higher $\mathrm{pH}$ values could be due to the formation of some hydroxyl complexes of $\mathrm{Gd}(\mathrm{III})$ and insoluble gadolinium hydroxide, that in both cases, the concentration of free $\mathrm{Gd}(\mathrm{III})$ reduces in the solution. At the lower $\mathrm{pH}$ values than 2.9, the potentials increase, indicating that the membrane sensor responds to hydrogen ions protonation of nitrogen atom in structure of MTH.

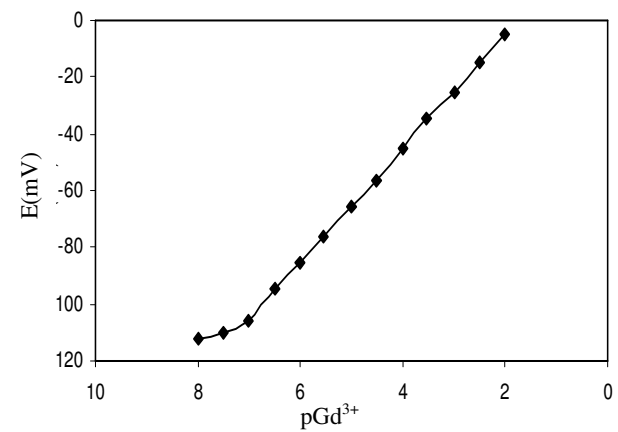

Figure 2. Calibration curves of the MTH -based gadolinium electrode

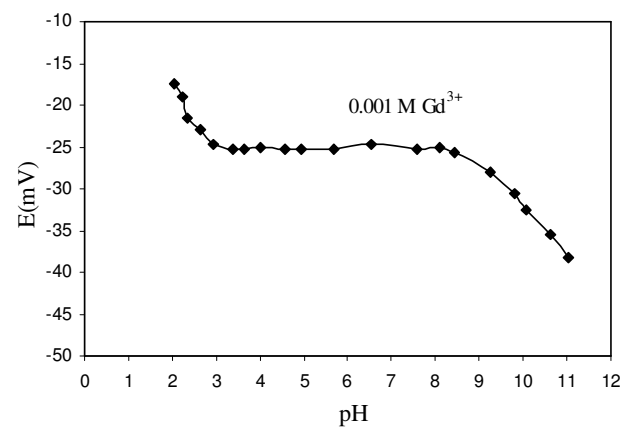

Figure 3. $\mathrm{pH}$ effect of the test solution $\left(1.0 \times 10^{-3} \mathrm{M}\right.$ of $\left.\mathrm{Gd}^{3+}\right)$ on the potential response of the $\mathrm{Gd}^{3+}$ ion-selective electrode

Dynamic response time is an important factor for any ion-selective electrode. In this study, the practical response time was recorded by changing the concentration of gadolinium 
ion in solution in the range of $1.0 \times 10^{-7}$ to $1.0 \times 10^{-2} \mathrm{M}$ and the results are shown in Figure 4. As can be seen, in the whole concentration range the electrode reaches its equilibrium response, very fast $(<10 \mathrm{~s})$.

The gadolinium membrane sensor was used as an indicator electrode in the successful titration of a gadolinium ion solution $\left(1.0 \times 10^{-4} \mathrm{M}\right)$ with EDTA $\left(1.0 \times 10^{-2} \mathrm{M}\right)$. The resulting titration curves are depicted in Figure 5. As seen from Figure 5, the amount of gadolinium can be determined with the proposed sensor.

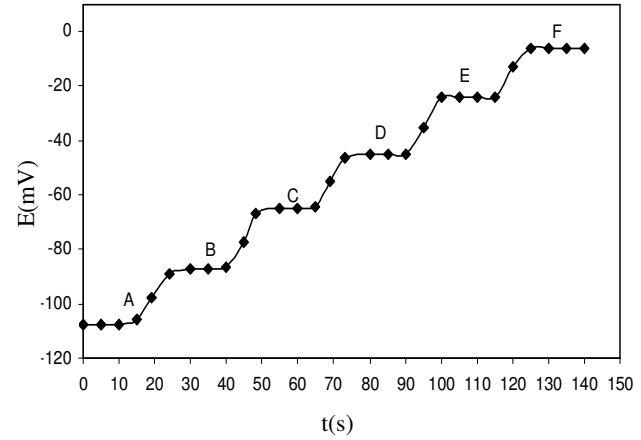

Figure 4. Dynamic response time of the gadolinium electrode for step changes in the $\mathrm{Gd}^{3+}$ concentration: A) $1.0 \times 10^{-7} \mathrm{M}, \mathrm{B}$ ) $1.0 \times 10^{-6} \mathrm{M}$, C) $1.0 \times 10^{-5} \mathrm{M}$, D) $1.0 \times 10^{-4} \mathrm{M}$, E) $1.0 \times 10^{-3} \mathrm{M}$, F) $1.0 \times 10^{-2} \mathrm{M}$

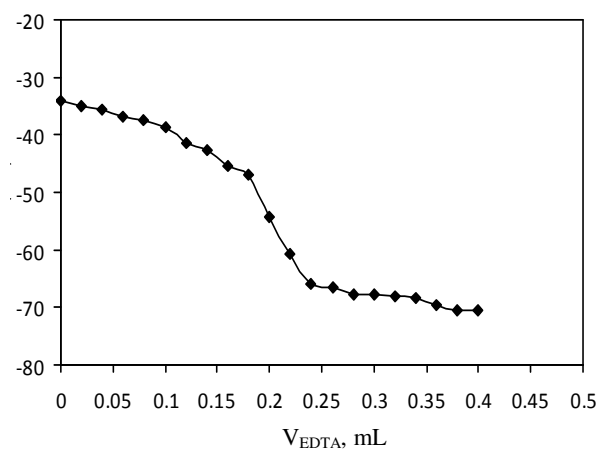

Figure 5. Potential titration curve of $20.0 \mathrm{~mL}$ from a $1.0 \times 10^{-4} \mathrm{M} \mathrm{Gd}^{3+}$ solution with $1.0 \times 10^{-2} \mathrm{M}$ of EDTA

\section{Acknowledgment}

The authors acknowledge the kind financial support provided by the Research Council of Quchan Branch Islamic Azad University for the preparation of this study.

\section{References}

1. Oesch U, Amman D and Simon W, Clin Chem., 1986, 32, 1448-1459.

2. Arnold M A and Meyerhoff M E, Anal Chem., 1984, 56, $20 \mathrm{R}$.

3. Davies M L, Hamilton C J, Murphy S M and Tighe B, J Biomaterials., 1992, 13(14), 971-978.

4. Faridbod F, Ganjali M R, Dinarvand R and Norouzi P, Comb Chem High Throughput Sc., 2007, 10(7), 527-546.

5. Zamani H A, Hamed-Mosavian M T, Aminzadeh E, Ganjali M R, Ghaemy M, Behmadi and Faridbod F, Desalination, 2010, 250, 56.

6. Zamani H A, Ganjali M.R, Norouzi P, Adib M and Aceedy M, Anal Sci., 2006, 22(7), 943-948.

7. Zamani H A, Rajabzadeh G and Ganjali M.R, Sensor Lett., 2009, 7, 114.

8. Zamani H A, Anal Lett., 2009, 42, 615.

9. Abedi M R and Zamani H A, Anal. Lett., 2008, 41, 2251.

10. Abedi M R, Zamani H A, Ganjali M R and Norouzi P, Sensor Lett., 2007, 5, 516.

11. Zamani H A, Ganjali M R, Norouzi P and Adib M, Sensor Lett., 2007, 5, 522.

12. Zamani H A, Mohammadhossieni M, Nekoei M and Ganjali M R, Sensor Lett., 2010, 8, 303.

13. Behmadi H, Zamani H A, Ganjali M R and Norouzi P, Electrochim Acta, 2007, 53, 1870. 
14. Zamani H A, Ganjali M R and Seifi N, Collect Czech Chem Commun., 2007, 72, 1189.

15. Ganjali M R, Norouzi P, Adib M and Ahmadalinezhad A, Anal Lett., 2006, 39, 1075.

16. Zamani H A, Ganjali M R, Norouzi P and Meghdadi S, J Appl Electrochem., 2007, 37, 853.

17. Zamani H A, Anal Lett., 2008, 41, 1850.

18. Zamani H A, Ganjali M R, Norouzi P, Tajarodi A and Hanifehpour Y, J Chil Chem Soc., 2007, 52, 1332.

19. Zamani H A, Masrournia M, Sahebnasagh S and Ganjali M R, Anal Lett., 2009, 42, 555.

20. Ganjali M R, Rahimi M, Maddah B, Moghimi A and Borhany S, Anal.Sci.., 2004, 20(10), 1427-1431.

21. Ganjali M R, Norouzi P, Daftari A, Faridbod F and Salavati-Niasari M, Sens Actuators B, 2007, 120, 673 .

22. Jones R G and Ainsworth C, J Am Chem Soc., 1955, 77, 1538.

23. Naddaf E and Zamani H A, Anal Lett., 2009, 42, 2838.

24. Zamani H A, Zabihi M S, Rohani M, Zangeneh-Asadabadi A, Ganjali M A, Faridbod F and Meghdadi S, Mater Sci Eng., C 2011, 31, 409.

25. Zamani H A, Arvinfar A, Rahimi F, Imani A, Ganjali M R and Meghdadi S, Mater. Sci Eng C, 2011, 31, 307.

26. Zamani H A, Rohani M, Zangeneh-Asadabadi A, Zabihi M S, Ganjali M R and Salavati-Niasari M, Mater Sci Eng., C 2010, 30, 917.

27. Masrournia M, Zamani H A, Mirrashid H A, Ganjali M R and Faridbod F, Mater Sci Eng C, 2011, 31, 574.

28. Zamani H A, Imani A, Arvinfar A, Rahimi F, Ganjali M R, Faridbod F and Meghdadi S, Mater Sci Eng C, 2011, 31, 588.

29. Zamani H A, Feizyzadeh B, Faridbod F and Ganjali M R, Sensor Lett., 2011, 9, 1767.

30. Zamani H A, Rohani M, Mohammadhosseini M, Ganjali M R, Faridbod F and Meghdadi S, Sensor Lett., 2011, 9, 1745.

31. Zamani H A, Ganjali M R, Norouzi P and Meghdadi S, Anal Lett., 2008, 41, 902.

32. Nekoei M, Zamani H A and Mohammadhossieni M, Anal Lett., 2009, 42, 284.

33. Mohammadhossieni M, Zamani H A and Nekoei M, Anal Lett., 2009, 42, 298.

34. Rosatzin T, Bakker E, Suzuki Y and Simon W, Anal Chim Acta, 1993, 280, 197.

35. Ammann E, Pretsch E, Simon W, Lindner E, Bezegh A and Pungor E, Anal Chim Acta, 1985, 171, 119-129.

36. Zamani H A, Ganjali M R, Norouzi P and Adib M, Mater Sci Eng C, 2008, 28, 157.

37. Zamani H A, Rajabzadeh G, Masrornia M, Dejbord A, Ganjali M R and Seifi N, Desalination, 2009, 249, 560.

38. Zamani H A, Rajabzadeh G, Firouz A and Ganjali M R, J Anal Chem., 2007, 62, 1080.

39. Eugster R, Gehring P M, Morf W E, Spichiger U E and Simon W, Anal Chem., 1991, 63, 2285-2289. 


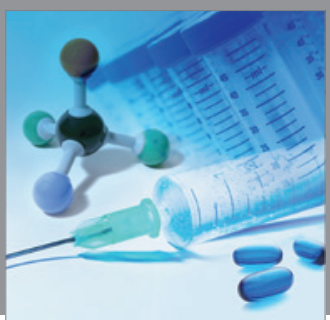

International Journal of

Medicinal Chemistry

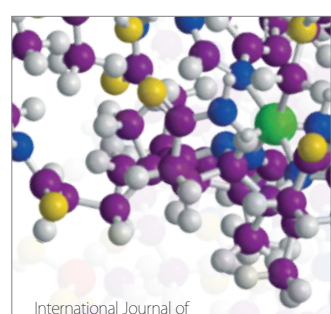

Carbohydrate Chemistry

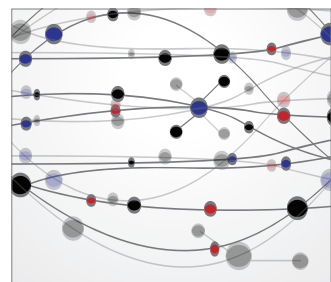

The Scientific World Journal
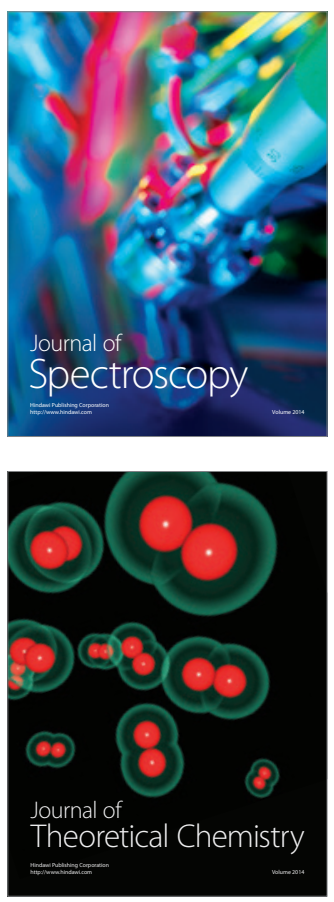
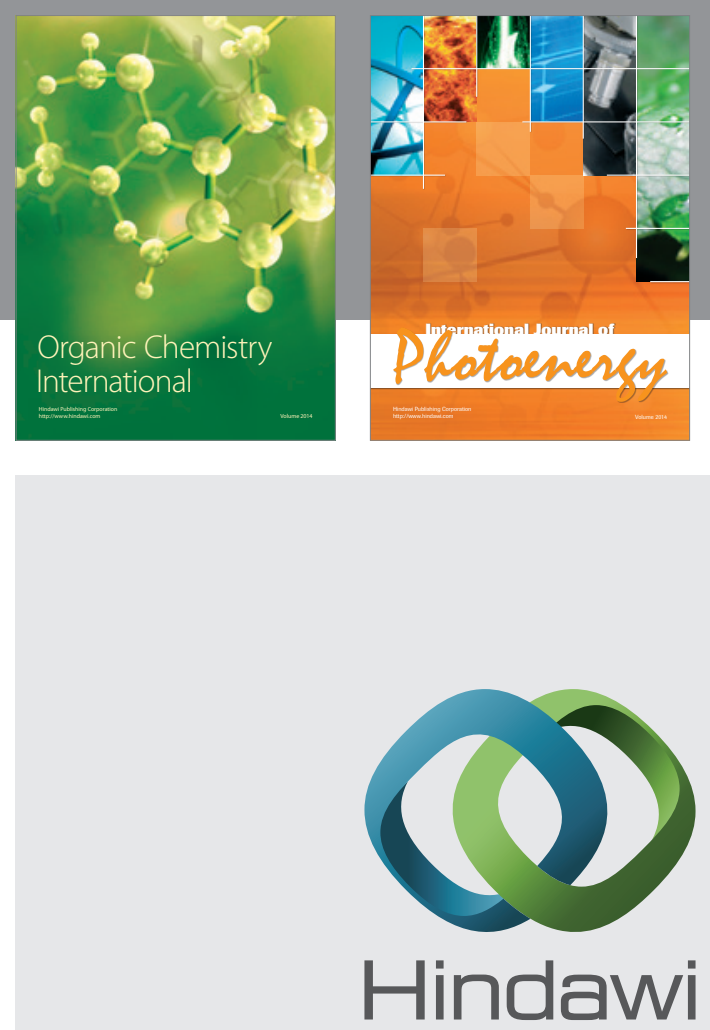

Submit your manuscripts at

http://www.hindawi.com
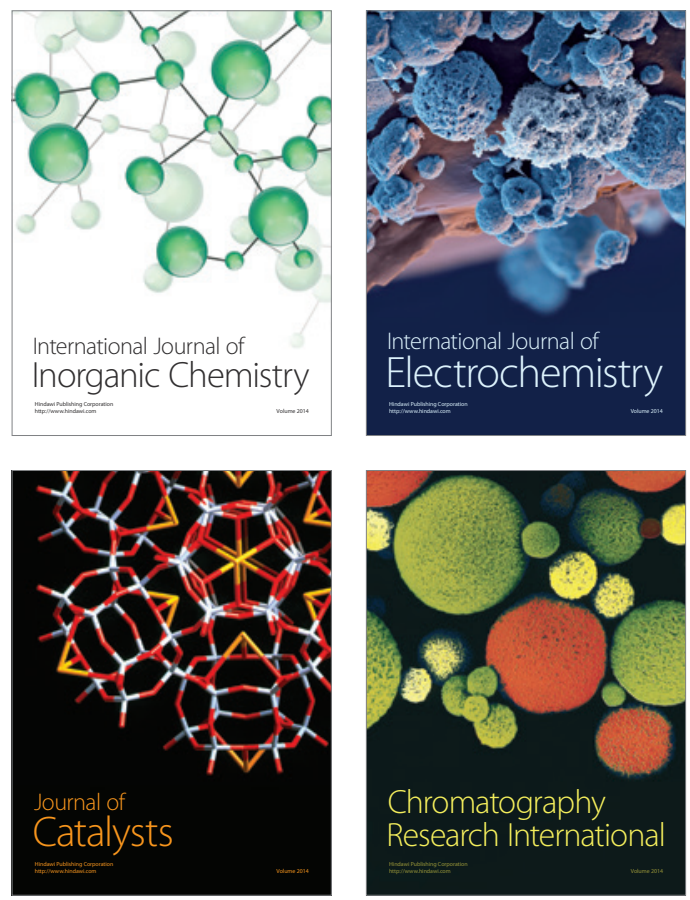
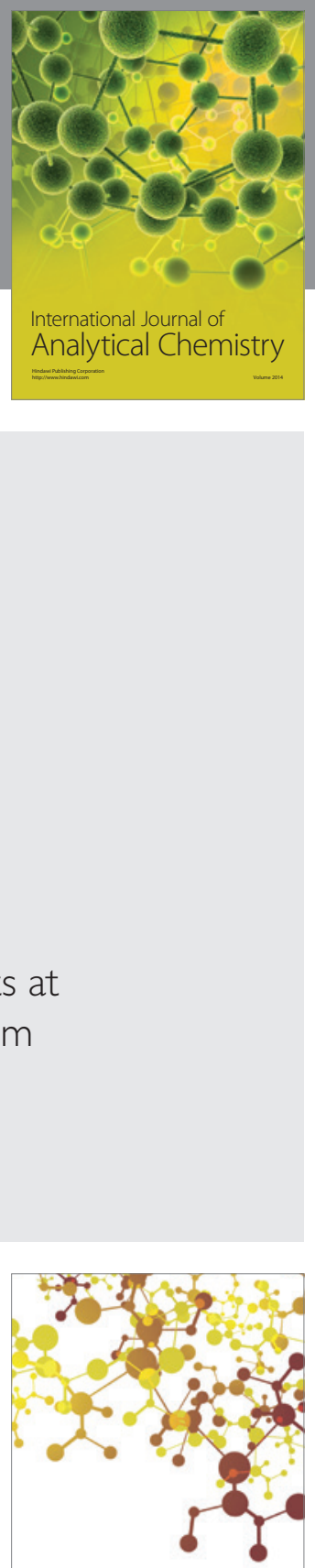

Journal of

Applied Chemistry
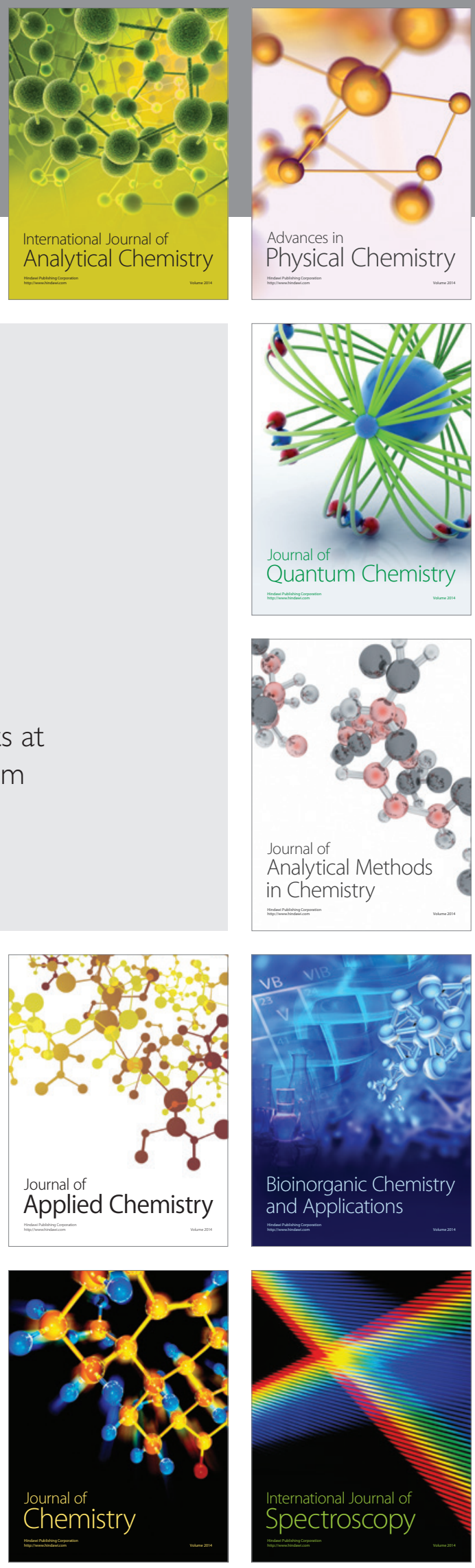